\title{
Primary Tumor Vascularity, HIF-1a and VEGF expression in vulvar squamous cell carcinomas: their relationships with clinicopathological characteristics and prognostic impact
}

\author{
Hari Prasad Dhakal', Jahn M Nesland ${ }^{1}$, Mette Førsund ${ }^{1}$, Claes G Trope ${ }^{2}$ and Ruth Holm*
}

\begin{abstract}
Background: Increased vascularity is a crucial event in the tumor progression and has prognostic significance in various cancers. However, the ultimate role of angiogenesis in the pathogenesis and clinical outcome of vulvar carcinoma patients is still not settled.

Methods: Tumor vascularity using CD34 stained slides measured by Chalkley counting method as well as hypoxiainducible factor (HIF)-1a and vascular endothelial growth factor (VEGF) immunoexpression was examined in 158 vulvar squamous cell carcinomas. Associations between vascular Chalkley count, HIF-1a and VEGF expression and clinicopathological factors and clinical outcome were evaluated.

Results: High CD34 Chalkley count was found to correlate with larger tumor diameter $(P=0.002)$, deep invasion $(P<0.001)$ and HIF-1a $(P=0.04)$, whereas high VEGF expression correlate significantly with poor tumor differentiation $(P=0.007)$. No significant association between CD34 Chalkley counts and VEGF expression and disease-specific survival was observed. High HIF-1a expression showed better disease specific survival in both univariate and multivariate analyses $(P=0.001)$.

Conclusions: A significant association between high tumor vascularity and larger tumor size as well as deeper tumor invasion suggests an important role of angiogenesis in the growth and progression of vulvar carcinomas. HIF-1 a expression in vulvar carcinomas was a statistically independent prognostic factor.
\end{abstract}

Keywords: Vulvar squamous cell carcinoma, HIF-1a, Immunohistochemistry, Tumor vascularity, Chalkley method

\section{Background}

Vulvar carcinoma is accounting for 3-5\% of all gynecological cancer and with an incidence ranging from 1 to 2 per 100000 person-years worldwide [1,2]. The median age of these patients has been about 70 years. However, recently vulvar carcinomas are seen more frequently in younger patients $[3,4]$. The prognostic evaluation and treatment of vulvar carcinoma patients have been primarily guided by the lymph node status, the size of the tumor, depth of invasion, stage of the disease and grades [5-7]. Radical surgery is the most common treatment, but is

\footnotetext{
* Correspondence: ruth.holm@oslo-universitetssykehus.no

'Department of Pathology, The Norwegian Radium Hospital, Oslo University Hospital and Medical Faculty, University of Oslo, Oslo, Norway

Full list of author information is available at the end of the article
}

often accompanied with physical and psychological adverse effects $[5,8]$. In an attempt to reduce severe complications, a change to individualized therapy has been reported [9]. Thus, identification of new markers which indicate the tumor behavior would be important to guide treatment decisions.

Angiogenesis is a crucial event for tumor growth and progression beyond a tumor size of $1-2 \mathrm{~mm}$. Therefore, tumor neovasculature makes an important target for antiangiogenic therapy $[10,11]$. Increased tumor vascularity has been shown to have prognostic significance in various cancers including vulvar cancer [12-15]. The role of increased tumor vascularity in disease progression of various malignant gynecologic lesions, including malignant vulvar lesions, has been described [16,17]. Its importance in

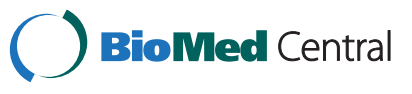


vulvar cancer has been emphasized by the increased vascularity in preinvasive lesions and invasive vulvar carcinomas [15-21]. Vulvar carcinoma patients with increased vascularity were reported to have poor prognosis in some studies $[6,15,19]$, whereas other showed no significance [20].

Hypoxia-inducible factor (HIF)- $1 \alpha$, a transcription factor, is a key regulator of angiogenesis when a growing tumor experiences hypoxic stress and acts through various intracellular signalling pathways. Such activation results in the secretion of vascular endothelial growth factor (VEGF) and other factors related to tumor metabolism necessary for hypoxia compensation and tumor cell survival [22]. It is known to be expressed in various solid tumors including vulvar squamous cell carcinomas [23-30]. The relation between primary tumor vascularity and HIF- $1 \alpha$ expression in head and neck and oesophageal squamous cell carcinoma has been reported $[24,25]$, and the prognostic impact of HIF- $1 \alpha$ expression in cancer is varied [26,27,29-32]. HIF-1 $\alpha$ expression investigated recently in normal epithelium, intraepithelial neoplasia and invasive carcinoma of vulva did not show significant differences [28]. To our knowledge, no study of HIF- $1 \alpha$ expression and its connection with prognosis in vulvar carcinoma patients has been reported. VEGF, a potent angiogenic molecule over-expressed in a hypoxic state, is crucial to induce tumor angiogenesis and acts through the receptors VEGFR1 and VEGFR2 [22,33]. It is expressed in various human cancers including vulvar malignancy $[21,28,34,35]$. A significant variation in expression of VEGF in nonneoplastic epithelium, preneoplastic lesions and invasive squamous cell carcinoma of vulva has been described [21,28,35]. Its expression in vulvar cancer and relationship with vascularity has been reported [19]. The prognostic impact of VEGF expression in invasive vulvar carcinoma is still not settled $[19,36]$.

In the present study, we have evaluated a large series of primary vulvar squamous cell carcinomas for primary tumor vascularity and expression of HIF- $1 \alpha$ and VEGF and elucidated their relationships with various clinicopathological parameters and clinical outcome.

\section{Methods}

\section{Patient materials}

A retrospective study was performed on a cohort of 158 patients with vulvar squamous cell carcinoma. All patients had undergone a resection at The Norwegian Radium Hospital between 1977 and 2006. The median age at diagnosis was 75 years (range, 41-92 years). In 108 $(68 \%)$ of these cases radical surgery (a total vulvectomy plus a bilateral inguinal lymphadenectomy) had been performed, whereas the remaining $50(32 \%)$ patients had non-radical surgery. Postoperative therapy had been administered to 44 patients including irradiation in 40 (25\%) cases and irradiation/chemotherapy in four (3\%) cases. Seventy-four (47\%) of the patients died as a result of their vulvar cancer. All patients were followed up from the time of their confirmed diagnosis until death or 1 . September, 2009. The median follow-up time for patients still alive was 108 months (range, 43 to 347 months). All tumors were staged based on the new International Federation of Gynecology and the Obstetrics (FIGO) classification from 2009 [37]. The Regional Committee for Medical Research Ethics South of Norway (S-06012), The Social and Health Directorate (04/2639 and 06/1478) and The Data Inspectorate (04/01043) approved the current study protocol. In this study we have used paraffin embedded tumor tissue from vulvar cancer patients diagnosed between 1977 and 2006. As many of these patients are dead or very old we did not have the opportunity to obtain patient consent. Permission to perform this study without patient consent was obtained from The Social and Health Directorate $(04 / 2639)$.

Histological specimens were reviewed by the coauthor J.M.N. without access to any clinical information on the patients. The tumors were classified according to the World Health Organization recommendations [38]. All 158 tumors were classified as keratinizing/non-keratinizing squamous cell carcinomas.

\section{Immunohistochemistry}

Three micrometer sections were processed for immunohistochemistry using the Dako EnVision ${ }^{\mathrm{Tm}}$ Flex+ System (K8012; Dako, Glostrup, Denmark) and the Dako Autostainer. Deparaffinization and the unmasking of epitopes were performed using PT-Link (Dako) and EnVision ${ }^{\text {Tu }}$ Flex target retrieval solution at a high $\mathrm{pH}$. After treatment with $0.03 \%$ hydrogen peroxide $\left(\mathrm{H}_{2} \mathrm{O}_{2}\right)$ for $5 \mathrm{~min}$ to block endogenous peroxidase activity, the sections were incubated with monoclonal antibodies raised against CD34 (30 min at room temperature, clone QBEND-10, 1:1000, $1 \mu \mathrm{g} \mathrm{IgG}_{1} / \mathrm{ml}$ ) purchased from Monosan (Uden, The Netherlands), HIF- $1 \alpha$ (over night at $4{ }^{\circ} \mathrm{C}$, clone $54 / \mathrm{HIF}-1 \alpha$, 1:100, $2.5 \mu \mathrm{g} \mathrm{IgG} / 1 \mathrm{ml}$ ) purchased from BD Transduction Laboratories $^{\text {tw }}$ (San Jose, CA, USA) and VEGF (over night at $4^{\circ} \mathrm{C}$, clone VG1, 1:100, $0.45 \mu \mathrm{g} \mathrm{IgG}_{1} / \mathrm{ml}$ ) purchased from Dako. Then the slides were incubated with EnVi$\operatorname{sion}^{\mathrm{Tm}}$ Flex+ mouse linker (15 min), EnVision ${ }^{\mathrm{Tw}}$ Flex/HRP enzyme (30 $\mathrm{min})$ and 3'3-diaminobenzidine tetrahydrochloride (DAB) (10 min). After counterstaining with hematoxylin the samples were dehydrated and mounted in Richard-Allan Scientific Cyto seal XYL (Thermo Scientific, Waltham, MA, USA). All of the sample series included positive controls known to be positive for CD34, HIF- $1 \alpha$ and VEGF. As negative controls, the primary antibodies were replaced with mouse myeloma protein $\operatorname{IgG}_{1}$ at the equivalent concentration. 


\section{Quantification of tumor vascularity}

Chalkley method was used for quantification of tumor vascularity as recommended in a consensus meeting [39]. The method has been described in detail earlier [14]. Three most vascularized areas in the CD34 stained tumor section known as "hotspots" were identified under the low power magnification after scanning first at $\times 40$ and then $\times 100$ magnification following the Weidner's method of selection of vascular hotspots [40]. Then a 25 point Chalkley eyepiece graticule fixed in one of the eyepieces of the microscope was applied to each vascular hotspot at $\times 200$ magnification [Chalkley grid area of $0.1886 \mathrm{~mm}^{2}$ (Nikon microscope, Eclipse E400)] in such a way that maximum number of black dots in Chalkley graticule fell on or within immunostained microvessels. The number of these dots that have fallen on or within the immunostained microvessels were counted in each selected hotspot area and recorded as Chalkley count. Sclerotic and necrotic area was avoided and count was done in only invasive carcinoma including margin. The highest count among the 3 hotspots counts from each tumor was used for further analyses. Measurement of vascularity was performed without the knowledge of clinicopathological data or clinical outcome.

\section{Evaluation for HIF-1 $a$ and VEGF expression}

Expression of HIF-1 $\alpha$ was evaluated on immunostained slides semiquantitatively into four classes and only nuclear immunoreactivity of the tumor cells was taken into account. Due to similar staining intensity of the HIF- $1 \alpha$ positive cases we did not consider the intensity of immunostaining. Based on the number of HIF- $1 \alpha$ positively stained tumor cells, tumors were grouped into: $0 \%$ of the cells; $<10 \%$ of the cells; $10-50 \%$ of the cells and $>50 \%$ of the cells. For further analyses, HIF- $1 \alpha$ expression in nucleus in more than $50 \%$ of the tumor cells was considered as high. VEGF positive cases showed different staining intensity and both intensity and number of positive tumor cells were evaluated. Cytoplasmic expression of VEGF was categorized semiquantitatively on the basis of intensity of the signal (absent, 0; weak, 1; moderate, 2; strong, 3) and the percentage of positive tumor cells (absent, $0 ;<10 \%, 1$; $10-50 \%, 2 ;>50 \%, 3)$. The composite score was calculated as fraction of positive tumor cells score multiplied by intensity score, and range from 0 to 9 . For further analyses, cytoplasmic VEGF immunostaining with a composite score $\geq 6$ was classified as high expression. Examination of immunostaining was performed in a blinded fashion with no knowledge of the clinicopathological variables and patient outcomes.

\section{Statistical analyses}

The associations between the HIF- $1 \alpha$ and VEGF expression and CD34 Chalkley counts of primary tumor vascularity and the clinicopathological variables were evaluated by the Pearson chi-square $\left(x^{2}\right)$, Fisher's exact test and linearby-linear association as required. The disease-specific survival analysis, based on death from vulvar cancer only, was performed using the Kaplan Meier method and $P$ value computed by log-rank test. A Cox proportional hazards regression model was used for both univariate and multivariate evaluation of survival rates. In the multivariate analysis, a backward regression was performed and variables with a $P \leq 0.05$ in univariate survival analysis were included in the model. The vulvar carcinoma tissues in our cohort have been collected over an extensive period from 1977-2006. Due to the large variation in storage time and given that the fixation protocol for these tissues up to 1987 was acid formalin, whereas from 1987-2006 was buffered formalin, Mann-Whitney $U$ test was performed to evaluate whether this has any influence on the CD34, HIF- $1 \alpha$ and VEGF immunostaining. The MannWhitney $\mathrm{U}$ test showed that the distribution of CD34,

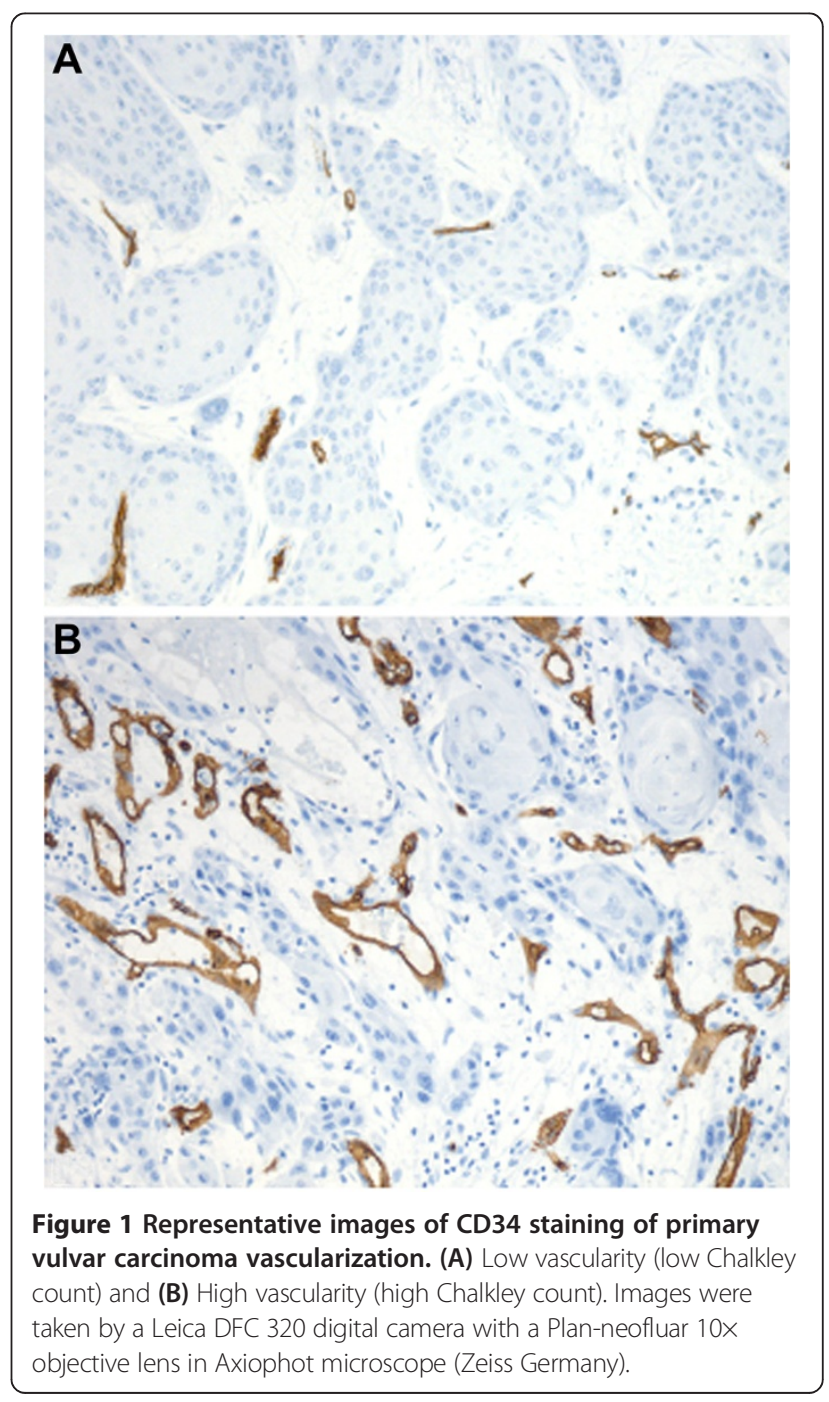


HIF- $1 \alpha$ and VEGF expression was the same between samples processed before and after 1987. All analyses were processed using the SPSS 18.0 statistical software package (SPSS, Chicago, IL). Statistical significance was considered for $P<0.05$.

\section{Results}

Vascularization in vulvar squamous cell carcinoma was heterogenously distributed. Microvessels were located in the tumor stroma lying between the islands of tumor cells and the size and shape of the vessels greatly varied. The CD34 Chalkley counts for the vulvar carcinoma vascularity ranged from 3-14 (mean, 7.92; median, 8; SD, 2.29). Predefined cutoff value of 8 (median value) was used to dichotomize the tumor into high and low vascular groups. Low (Chalkley counts $<8$ ) and high (Chalkley counts $\geq 8$ ) vascularity was identified in $67(42 \%)$ and 91 (58\%) of the vulvar carcinomas, respectively (Figure 1A and B). In vulvar carcinomas, high HIF- $1 \alpha$ immunostaining (> 50\% tumor cells) in the nucleus was observed in 57 $(36 \%)$ and low levels ( $\leq 50 \%$ tumor cells) in $101(64 \%)$ cases (Figure 2A and B), whereas high VEGF expression (score $\geq 6$ ) in the cytoplasm was identified in $63(40 \%)$ and low low level $($ score $<6$ ) in $95(60 \%)$ cases (Figure 2C and D).

CD34 Chalkley count, HIF-1 $\alpha$ and VEGF expression in relation to clinicopathological parameters are shown in Table 1. High CD34 Chalkley count was found to correlate significantly with larger tumor diameter $(P=0.002)$ and deeper invasion $(P<0.001)$, whereas high VEGF expression correlate significantly with poor tumor diffe- rentiation $(P=0.007)$. High level of HIF- $1 \alpha$ was significantly correlated to high CD34 Chalkley counts $(P=0.04)$. VEGF expression did not show any association with CD34 Chalkley count and HIF-1 $\alpha$ levels.

In univariate survival analysis, high HIF-1 $\alpha$ expression was associated with better disease-specific survival $(P=0.001)$ (Figure 3), whereas no significant association between CD34 Chalkley counts and VEGF expression and diseasespecific survival $(P=0.16$ and $P=0.45$, respectively) was observed. In multivariate analysis, lymph node metastases, age and HIF- $1 \alpha$ expression retained independent prognostic significance (Table 2).

\section{Discussion}

We observed that primary tumor vascularity, quantified by Chalkley method, had a significant association with tumor size and depth of invasion in invasive vulvar carcinomas. Tumor size has been reported to predict local lymph node metastasis [41] and is an important prognostic marker in vulvar cancer patients. Tumor size is at present used to stratify patients into different risk groups and acts as a determinant for surgical treatment [6,7]. In vulvar carcinomas, depth of tumor invasion is also indicative of the aggressiveness of primary tumor and is reported to be associated with lymph node metastases [41] and reduced survival [6]. Inguinofemoral lymph node status is the most powerful indicator of poor prognosis in vulvar cancer [42-44] and a significantly reduced survival in the current study has been confirmed. In the present study, no prognostic significance of tumor vascularity was observed for patients with vulvar carcinoma.

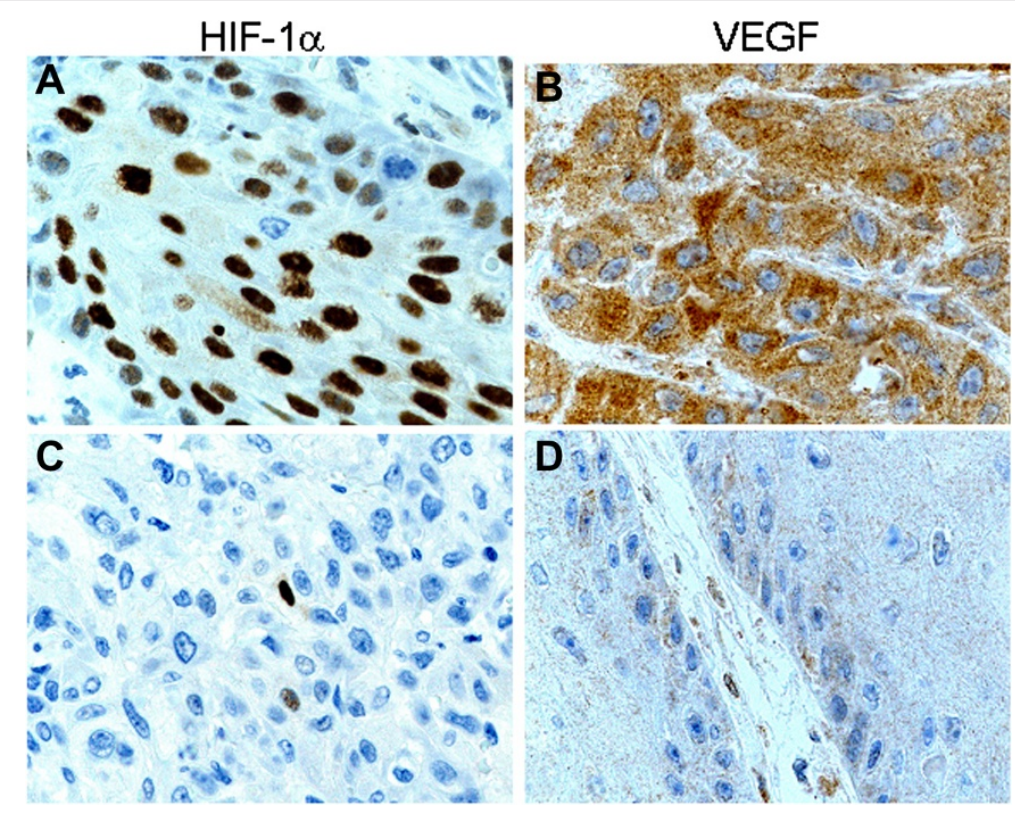

Figure 2 Representative images of HIF-1a and VEGF immunoexpression in primary vulvar carcinoma. (A) high HIF-a nuclear expression and (B) low HIF-a nuclear expression (C) high VEGF cytoplasmic staining and (D) low VEGF cytoplasmic staining. 40x objective lens. 
Table 1 CD34 Chalkley count, HIF-1a and VEGF expression in relation to clinicopathological variables in vulvar carcinomas

\begin{tabular}{|c|c|c|c|c|c|c|c|c|c|c|}
\hline \multirow[t]{2}{*}{ Variable } & \multirow{2}{*}{$\begin{array}{l}\text { Total } \\
\text { N }\end{array}$} & \multicolumn{3}{|c|}{ CD34 Chalkley count } & \multicolumn{3}{|c|}{ HIF-1a } & \multicolumn{3}{|c|}{ VEGF } \\
\hline & & Low & High (\%) & $P$ value & Low & High (\%) & $P$ value & Low & High (\%) & $P$ value \\
\hline$\overline{\text { Age }}$ & & & & $0.25^{1}$ & & & $0.28^{1}$ & & & $0.68^{1}$ \\
\hline $25-69$ & 59 & 30 & $29(49)$ & & 34 & $25(42)$ & & 36 & $23(39)$ & \\
\hline $70-84$ & 81 & 29 & $52(64)$ & & 55 & $26(32)$ & & 46 & $35(43)$ & \\
\hline $85+$ & 18 & 8 & $10(56)$ & & 12 & $6(33)$ & & 13 & $5(28)$ & \\
\hline $\mathrm{FIGO}$ & & & & $0.67^{2}$ & & & $0.22^{2}$ & & & $0.08^{2}$ \\
\hline la & 0 & 0 & $0(0)$ & & 0 & $0(0)$ & & 0 & $0(0)$ & \\
\hline $\mathrm{lb}$ & 77 & 35 & $42(55)$ & & 51 & $26(34)$ & & 48 & $29(38)$ & \\
\hline$\|$ & 7 & 2 & $5(71)$ & & 4 & $3(43)$ & & 7 & $0(0)$ & \\
\hline Illa & 30 & 14 & $16(53)$ & & 13 & $17(57)$ & & 20 & $10(33)$ & \\
\hline$\| l l b$ & 26 & 8 & $18(69)$ & & 18 & $8(31)$ & & 11 & $15(58)$ & \\
\hline Illc & 7 & 2 & $5(71)$ & & 5 & $2(29)$ & & 4 & $3(43)$ & \\
\hline IVa & 1 & 1 & $0(0)$ & & 1 & $0(0)$ & & 0 & $1(100)$ & \\
\hline $\mathrm{IVb}$ & 7 & 3 & $4(57)$ & & 6 & $1(14)$ & & 4 & $3(43)$ & \\
\hline Not available & 3 & & & & & & & & & \\
\hline Lymph node metastasis & & & & $0.21^{3}$ & & & $0.54^{3}$ & & & $0.11^{3}$ \\
\hline None & 87 & 39 & $48(55)$ & & 58 & $29(33)$ & & 55 & $31(37)$ & \\
\hline Unilateral & 44 & 19 & $25(57)$ & & 25 & $19(43)$ & & 29 & $15(34)$ & \\
\hline Bilateral & 24 & 6 & $18(75)$ & & 15 & $9(38)$ & & 10 & $14(58)$ & \\
\hline Not available & 3 & & & & & & & & & \\
\hline Tumor diameter $(\mathrm{cm})$ & & & & $0.002^{1}$ & & & $0.95^{1}$ & & & $0.98^{1}$ \\
\hline $0.3-2.5$ & 32 & 19 & $13(41)$ & & 19 & $13(41)$ & & 20 & $12(38)$ & \\
\hline $2.6-4.0$ & 51 & 24 & $27(53)$ & & 33 & $16(31)$ & & 30 & $21(41)$ & \\
\hline $4.1-20.0$ & 72 & 21 & $51(71)$ & & 44 & $28(39)$ & & 44 & $28(39)$ & \\
\hline Not available & 3 & & & & & & & & & \\
\hline Tumor differentiation & & & & $0.07^{3}$ & & & $0.23^{3}$ & & & $0.007^{3}$ \\
\hline Well & 35 & 19 & $16(46)$ & & 26 & $9(26)$ & & 19 & $16(46)$ & \\
\hline Moderate & 92 & 32 & $60(65)$ & & 54 & $38(41)$ & & 64 & $28(30)$ & \\
\hline Poor & 31 & 16 & $15(48)$ & & 21 & $10(32)$ & & 12 & $19(61)$ & \\
\hline Depth of invasion (mm) & & & & $<0.001^{1}$ & & & $0.58^{1}$ & & & $0.78^{1}$ \\
\hline $0.0-4.0$ & 26 & 19 & $7(27)$ & & 17 & $9(35)$ & & 15 & $11(42)$ & \\
\hline $4.1-8.0$ & 56 & 26 & $30(54)$ & & 37 & $19(34)$ & & 37 & $19(34)$ & \\
\hline $8.1-40.0$ & 74 & 20 & $54(73)$ & & 45 & $29(39)$ & & 43 & $31(42)$ & \\
\hline Not available & 2 & & & & & & & & & \\
\hline Infiltration of vessel & & & & $0.55^{3}$ & & & $0.06^{3}$ & & & $0.73^{3}$ \\
\hline No & 116 & 51 & $65(56)$ & & 70 & $46(40)$ & & 72 & $44(38)$ & \\
\hline Yes & 39 & 15 & $24(62)$ & & 30 & $9(23)$ & & 23 & $16(41)$ & \\
\hline Not available & 3 & & & & & & & & & \\
\hline
\end{tabular}

${ }^{1}$ Linear-by-linear association

${ }^{2}$ Fisher's exact test.

${ }^{3}$ Pearson chi-square.

Low: CD34 Chalkley count < 8; High: CD34 Chalkley count $\geq 8$.

Low: HIF-1a in $\leq 50 \%$ tumor cells; High: HIF-1a in $>50 \%$ tumor cells.

Low: VEGF score $<6$, High: VEGF score $\geq 6$. 


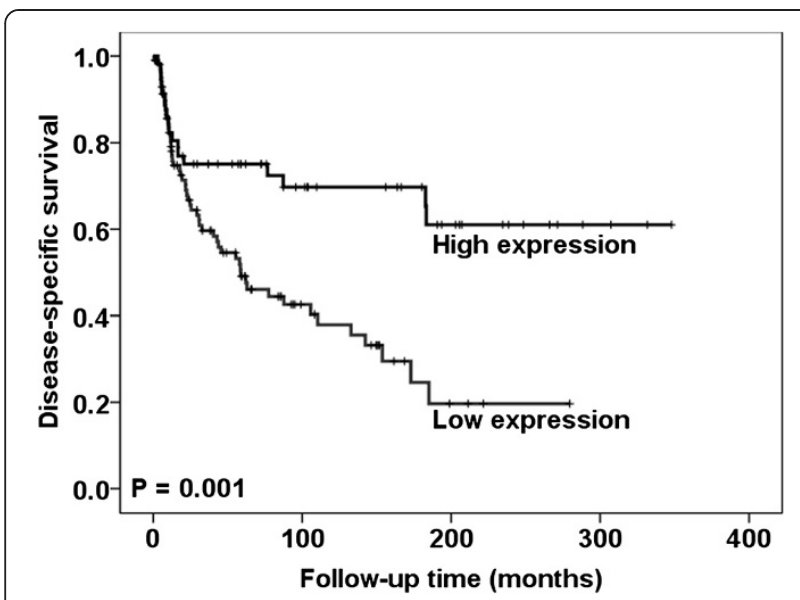

Figure 3 Survival curves using the Kaplan-Meier method. The Kaplan-Meier curve of disease-specific survival in relation to the HIF1a showed that patients whose tumors expressed low levels of HIFla had a worse prognosis than those with high levels.

This is in accordance with an earlier study on vulvar cancer [20], but in contrast to others $[6,15,19]$. These conflicting reports on primary tumor vascularity and prognosis might be due to methodological differences, different study cohort or biological factors $[6,19,20]$. We used the Chalkley counting method for vascular quantification which measures the relative vascular area [45], as recommended in a consensus meeting for quantification of vascularity in solid tumors [39], whereas in other studies microvessels have been counted manually $[15,19,20]$ or using image analyses [6]. Moreover, other studies $[6,15,19,20]$ had analysed smaller number of cases compared to our large series of vulvar carcinomas. Thus, our results of high tumor vascularity associated with larger tumor size and deeper invasion (known pathological markers for tumor aggressiveness) indicates angiogenesis as a marker for the aggressive behaviour of vulvar carcinoma.

HIF- $1 \alpha$, is a crucial molecule in inducing angiogenesis in growing tumor under hypoxic stress [22] and several reports have been published on relation between HIF- $1 \alpha$ expression and angiogenesis in head and neck and oesophageal squamous cell carcinoma [24,25]. In present study, we did observe a positive association between HIF- $1 \alpha$ expression and CD34 Chalkey count of primary tumor vascularity similar to a report for head and neck squamous cell carcinoma patients [25]. This confirms the role of HIF- $1 \alpha$ for the initiation and the promotion of angiogenesis in vulvar cancer. High tumoral HIF- $1 \alpha$ expression is reported to be associated with reduced survival in oral, oropharyngeal and cervical cancers [29,32,46]. In contrast, in the present study, a significantly improved survival of vulvar carcinoma patients with high HIF- $1 \alpha$ expression was observed as reported for the squamous cell caricnoma in head and neck region, oral cavity and uterine cervix $[26,27,30,31]$. Other did not find prognostic significance in oesophageal squamous cell carcinoma [47]. Various factors are thought to affect the impact of HIF- $1 \alpha$ activation in tumor behaviour [48] including methodology, cut off(s) and treatment modalities [26,27,30-32,47]. Lack of CAIX and Glut-I expression along with high HIF- $1 \alpha$ expression in squamous cell carcinoma indicates alternative mechanism for HIF-1 $\alpha$ upregulation [26]. Furthermore, we have shown that the patients in good prognosis group had $>50 \%$ HIF- $1 \alpha$ positive tumor cells as reported for its strong expression in squamous cell carcinoma of oral cavity [27]. Diffuse HIF- $1 \alpha$ expression based on tumor types and its nonhypoxic activation through various genetic alterations that might result in different outcomes $[22,26]$ may also explain our observation. Vascularization was heterogenously distributed in the tumor including tumor fronts and in the stromal tissue between the islands of tumor cells. Perinecrotic tumor cells distant from the supplying vessels under hypoxic stress express HIF- $1 \alpha$, whereas nonnecrotic tumor shows diffuse expression throughout the tumor including the tumor cells close to the blood vessels [29]. Despite, the heterogenous distribution of vascularity, our observation of positive association between HIF- $1 \alpha$ and tumor vascularity suggests the HIF$1 \alpha$ induced angiogenesis. HIF-1 $\alpha$ is known to induce expression of various genes including genes linked to cell survival, apoptosis, cellular proliferation [22]. Perhaps, the better outcome in patients with high HIF- $1 \alpha$ expressing

Table 2 Relative risk (RR) of dying from vulvar cancer

\begin{tabular}{|c|c|c|c|c|c|c|}
\hline \multirow[t]{2}{*}{ Variables } & \multicolumn{3}{|c|}{ Univariate analysis } & \multicolumn{3}{|c|}{ Multivariate analysis } \\
\hline & RR & $95 \% \mathrm{Cl}^{\mathrm{a}}$ & $p$ & RR & $95 \% \mathrm{Cl}^{\mathrm{a}}$ & $p$ \\
\hline Lymph node metastasis & 1.99 & $1.49-2.65$ & $<0.001$ & 2.28 & $1.69-3.07$ & $<0.001$ \\
\hline Infiltration of vessel & 2.20 & $1.36-3.58$ & 0.001 & - & - & - \\
\hline Age & 1.70 & $1.20-2.41$ & 0.003 & 1.92 & $1.31-2.81$ & 0.001 \\
\hline Tumor diameter & 1.40 & $1.03-1.91$ & 0.03 & - & - & - \\
\hline$H I F-1 a^{b}$ & 2.49 & $1.45-4.28$ & 0.001 & 2.53 & $1.46-4.37$ & 0.001 \\
\hline
\end{tabular}

${ }^{\mathrm{a}} 95 \%$ confidence interval.

bLow: $\leq 50 \%$ tumor cells and high: $>50 \%$ tumor cells. 
tumors might be due to its inhibitory role on tumor cells through induction of proapoptotic pathway [49,50].

Hypoxia markers; HIF-1 $\alpha$, GLUT-1, CA IX and VEGF are expressed in both vulvar preneoplastic lesions and invasive squamous cell carcinoma [28]. An increasing expression of VEGF from normal epithelium to premalignant lesion to invasive squamous cell carcinoma was found in vulva [28]. In the present study, high VEGF expression was significantly associated with only poor tumor differentiation, however, an other study reported no such association in vulvar carcinomas [19]. We did not find that the VEGF levels demonstrated prognostic significance, a result being different from a report by Obermair and colleagues [19]. A lack of correlation of VEGF with vascularity observed in the present series which is different from an earlier report [19], might be due to its possible non-angiogenic effects and/or autocrine role on tumor cells [51,52]. Alternative mechanisms of VEGF independent neoangiogenesis by inducing other potent angiogenic molecules like basic fibroblast growth factor and size related proainherent angiogenic effect on the tumor [53] may have resulted in nonsignificant relationship. We noted no association between VEGF and HIF-1 $\alpha$ expression possibly due to an alternative non HIF- $1 \alpha$ mechanism of VEGF induction [54]. The proangiogenic effect of VEGF is closely related to the tumor size and no impact on angiogenesis is found when tumor reaches to certain size [53].

There are several pitfalls associated to immunohistochemical methods. In addition, the handling of tissue specimens, such as fixation and storage time, may influence the immunohistochemical results [55]. The lack of consideration for these limitations may reduce the usefulness of immunohistochemical studies. In the present study, the fixation and storage time of the tissues did not influence the CD34, HIF- $1 \alpha$ and VEGF immunostaining. Both false positive and negative results may limit the outcome of immunohistochemical studies. To reduce the possibility of false negative results we have used the EnVision ${ }^{\text {Ta }}$ Flex+ detection system reported to have a high sensitivity [56]. Furthermore, we have included positive controls in each run to exclude the possibility of false negative result due to methodological problems. To avoid nonspecific staining we extensively optimalized the dilutions of the primary antibodies used. In addition, negative controls, replacing the primary antibodies with the mouse myeloma protein $\mathrm{IgG}_{1}$, were included to exclude the possibility of false positive results. Despite the effort to quality secure immunostaining processes there are major limitations connected to immunohistochemistry between the studies that are linked to methodological differences including immunostaining procedures and scoring systems [57]. In the future it is clearly needed a standarization of immunohistochemical methodology and scoring systems.

\section{Conclusions}

Our results show that high tumor vascularity in vulvar carcinoma is associated with larger tumor size and deeper invasion, indicating that it is a feature of aggressive tumor phenotype. High HIF-1 $\alpha$ expression has favorable prognostic impact in vulvar carcinoma patients.

\section{Competing interests}

Authors declare that they have no competing interests.

\section{Author' contributions}

HPD participated in the design of the study, quantified tumor vascularity and draft the manuscript. JMN participated in the design of the study, performed systematic pathologic review of vulvar carcinomas and revised the manuscript critically. MF carried out the immunohistochemistry and revised the manuscript critically. CGT collected clinical data, participated in interpretation of data and revised the manuscript critically. $\mathrm{RH}$ participated in the design of the study, protein, statistical and data analysis and helped to draft the manuscript. All authors read and approved the final manuscript.

\section{Acknowledgements}

This work was supported by the Inger and John Fredriksen Foundation for Ovarian Cancer Research and the Norwegian Cancer Society.

\section{Author details}

${ }^{1}$ Department of Pathology, The Norwegian Radium Hospital, Oslo University Hospital and Medical Faculty, University of Oslo, Oslo, Norway. ${ }^{2}$ Department of Obstetrics and Gynecology, The Norwegian Radium Hospital, Oslo University Hospital and Medical Faculty, University of Oslo, Oslo, Norway.

Received: 12 June 2013 Accepted: 23 October 2013

Published: 29 October 2013

\section{References}

1. Giles $G G$, Kneale BL: Vulvar cancer: the Cinderella of gynaecological oncology. Aust N Z J Obstet Gynaecol 1995, 35:71-75.

2. Coulter J, Gleeson N: Local and regional recurrence of vulval cancer: management dilemmas. Best Pract Res Clin Obstet Gynaecol 2003, 17:663-681.

3. Jones RW, Baranyai J, Stables S: Trends in squamous cell carcinoma of the vulva: the influence of vulvar intraepithelial neoplasia. Obstet Gynecol 1997, 90:448-452.

4. Messing MJ, Gallup DG: Carcinoma of the vulva in young women. Obstet Gynecol 1995, 86:51-54.

5. Beller U, Quinn MA, Benedet JL, Creasman WT, Ngan HY, Maisonneuve P, Pecorelli S, Odicino F, Heintz AP: Carcinoma of the vulva. FIGO 26th Annual Report on the Results of Treatment in Gynecological Cancer. Int J Gynaecol Obstet 2006, 95(1):S7-27.

6. Nayha W, Stenback FG: Increased angiogenesis is associated with poor prognosis of squamous cell carcinoma of the vulva. Acta Obstet Gynecol Scand 2007, 86:1392-1397.

7. Wang Z, Trope CG, Florenes VA, Suo Z, Nesland JM, Holm R: Overexpression of CDC25B, CDC25C and phospho-CDC25C (Ser216) in vulvar squamous cell carcinomas are associated with malignant features and aggressive cancer phenotypes. BMC Cancer 2010, 10:233.

8. Tyring SK: Vulvar squamous cell carcinoma: guidelines for early diagnosis and treatment. Am J Obstet Gynecol 2003, 189:S17-S23.

9. Stehman FB, Look KY: Carcinoma of the vulva. Obstet Gynecol 2006, 107:719-733.

10. Folkman J: What is the evidence that tumors are angiogenesis dependent? J Natl Cancer Inst 1990, 82:4-6.

11. Folkman J: Angiogenesis: an organizing principle for drug discovery? Nat Rev Drug Discov 2007, 6:273-286.

12. Vermeulen PB, Libura M, Libura J, O'Neill PJ, Van DP, Van ME, Van Oosterom AT, Dirix LY: Influence of investigator experience and microscopic field size on microvessel density in node-negative breast carcinoma. Breast Cancer Res Treat 1997, 42:165-172.

13. Offersen BV, Borre M, Overgaard J: Quantification of angiogenesis as a prognostic marker in human carcinomas: a critical evaluation of 
histopathological methods for estimation of vascular density. Eur $J$ Cancer 2003, 39:881-890.

14. Dhakal HP, Naume B, Synnestvedt M, Borgen E, Kaaresen R, Schlichting E, Wiedswang G, Bassarova A, Giercksky KE, Nesland JM: Vascularization in primary breast carcinomas: its prognostic significance and relationship with tumor cell dissemination. Clin Cancer Res 2008, 14:2341-2350.

15. Hantschmann P, Jeschke U, Friese K: TGF-alpha, c-erbB-2 expression and neoangiogenesis in vulvar squamous cell carcinoma. Anticancer Res 2005, 25:1731-1737.

16. Abulafia O, Triest WE, Sherer DM: Angiogenesis in malignancies of the female genital tract. Gynecol Oncol 1999, 72:220-231.

17. Saravanamuthu J, Reid WM, George DS, Crow JC, Rolfe KJ, MacLean AB, Perrett CW: The role of angiogenesis in vulvar cancer, vulvar intraepithelial neoplasia, and vulvar lichen sclerosus as determined by microvessel density analysis. Gynecol Oncol 2003, 89:251-258.

18. Bancher-Todesca D, Obermair A, Bilgi S, Kohlberger P, Kainz C, Breitenecker G, Leodolter S, Gitsch G: Angiogenesis in vulvar intraepithelial neoplasia. Gynecol Oncol 1997, 64:496-500.

19. Obermair A, Kohlberger $P$, Bancher-Todesca D, Tempfer C, Sliutz G, Leodolter S, Reinthaller A, Kainz C, Breitenecker G, Gitsch G: Influence of microvessel density and vascular permeability factor/vascular endothelial growth factor expression on prognosis in vulvar cancer. Gynecol Oncol 1996, 63:204-209.

20. Qureshi F, Munkarah A, Banerjee M, Jacques SM: Tumor angiogenesis in vulvar squamous cell carcinoma. Gynecol Oncol 1999, 72:65-70.

21. Raspollini MR, Asirelli G, Taddei GL: The role of angiogenesis and COX-2 expression in the evolution of vulvar lichen sclerosus to squamous cell carcinoma of the vulva. Gynecol Oncol 2007, 106:567-571.

22. Semenza GL: Targeting HIF-1 for cancer therapy. Nat Rev Cancer 2003, 3:721-732.

23. Zhong H, De Marzo AM, Laughner E, Lim M, Hilton DA, Zagzag D, Buechler $P$, Isaacs WB, Semenza GL, Simons JW: Overexpression of hypoxiainducible factor 1alpha in common human cancers and their metastases. Cancer Res 1999, 59:5830-5835.

24. Kimura S, Kitadai Y, Tanaka S, Kuwai T, Hihara J, Yoshida K, Toge T, Chayama K: Expression of hypoxia-inducible factor (HIF)-1alpha is associated with vascular endothelial growth factor expression and tumour angiogenesis in human oesophageal squamous cell carcinoma. Eur J Cancer 2004, 40:1904-1912.

25. Koukourakis MI, Giatromanolaki A, Sivridis E, Simopoulos C, Turley H, Talks K, Gatter KC, Harris AL: Hypoxia-inducible factor (HIF1A and HIF2A), angiogenesis, and chemoradiotherapy outcome of squamous cell headand-neck cancer. Int J Radiat Oncol Biol Phys 2002, 53:1192-1202.

26. Fillies T, Werkmeister R, van Diest PJ, Brandt B, Joos U, Buerger H: HIF1-alpha overexpression indicates a good prognosis in early stage squamous cell carcinomas of the oral floor. BMC Cancer 2005, 5:84

27. dos Santos M, Mercante AM, Louro ID, Goncalves AJ, de Carvalho MB, da Silva EH, da Silva AM: HIF1-alpha expression predicts survival of patients with squamous cell carcinoma of the oral cavity. PLoS One 2012, 7:e45228.

28. Li YZ, Li SL, Li X, Wang LJ, Wang JL, Xu JW, Wu ZH, Gong L, Zhang XD: Expression of endogenous hypoxia markers in vulvar squamous cell carcinoma. Asian Pac J Cancer Prev 2012, 13:3675-3680.

29. Aebersold DM, Burri P, Beer KT, Laissue J, Djonov V, Greiner RH, Semenza GL: Expression of hypoxia-inducible factor-1alpha: a novel predictive and prognostic parameter in the radiotherapy of oropharyngeal cancer. Cancer Res 2001, 61:2911-2916.

30. Beasley NJ, Leek R, Alam M, Turley H, Cox GJ, Gatter K, Millard P, Fuggle S, Harris AL: Hypoxia-inducible factors HIF-1alpha and HIF-2alpha in head and neck cancer: relationship to tumor biology and treatment outcome in surgically resected patients. Cancer Res 2002, 62:2493-2497.

31. Hutchison GJ, Valentine HR, Loncaster JA, Davidson SE, Hunter RD, Roberts SA, Harris AL, Stratford IJ, Price PM, West CM: Hypoxia-inducible factor 1alpha expression as an intrinsic marker of hypoxia: correlation with tumor oxygen, pimonidazole measurements, and outcome in locally advanced carcinoma of the cervix. Clin Cancer Res 2004, 10:8405-8412.

32. Lin PY, Yu CH, Wang JT, Chen HH, Cheng SJ, Kuo MY, Chiang CP: Expression of hypoxia-inducible factor- 1 alpha is significantly associated with the progression and prognosis of oral squamous cell carcinomas in Taiwan. J Oral Pathol Med 2008, 37:18-25.
33. Ferrara N, Gerber HP, LeCouter J: The biology of VEGF and its receptors. Nat Med 2003, 9:669-676.

34. Jubb AM, Pham TQ, Hanby AM, Frantz GD, Peale FV, Wu TD, Koeppen HW Hillan KJ: Expression of vascular endothelial growth factor, hypoxia inducible factor 1alpha, and carbonic anhydrase IX in human tumours. J Clin Pathol 2004, 57:504-512.

35. Doldi N, Origoni M, Bassan M, Ferrari D, Rossi M, Ferrari A: Vascular endothelial growth factor. Expression in human vulvar neoplastic and nonneoplastic tissues. J Reprod Med 1996, 41:844-848.

36. Knopp S, Trope C, Nesland JM, Holm R: A review of molecular pathological markers in vulvar carcinoma: lack of application in clinical practice. $J$ Clin Pathol 2009, 62:212-218

37. Pecorelli S: Revised FIGO staging for carcinoma of the vulva, cervix, and endometrium. Int J Gynaecol Obstet 2009, 105:103-104.

38. Wilkinson EJaTMR: Tumours of the vulva. Epithelial tumours. In World Health Organization Classification of Tumours. Pathology and genetics of tumors of the breast and female genital organs. Edited by Tavassoli FA, Devilee P. Lyon: ARC Press; 2003:316-325.

39. Vermeulen PB, Gasparini G, Fox SB, Colpaert C, Marson LP, Gion M, Belien JA, de Waal RM, Van ME, Magnani E, Weidner N, Harris AL, Dirix LY: Second international consensus on the methodology and criteria of evaluation of angiogenesis quantification in solid human tumours. Eur $J$ Cancer 2002, 38:1564-1579.

40. Weidner N, Semple JP, Welch WR, Folkman J: Tumor angiogenesis and metastasis-correlation in invasive breast carcinoma. N Engl J Med 1991, 324:1-8.

41. Binder SW, Huang I, Fu YS, Hacker NF, Berek JS: Risk factors for the development of lymph node metastasis in vulvar squamous cell carcinoma. Gynecol Oncol 1990, 37:9-16.

42. der SS V, De Nieuwenhof HP, Massuger L, Bulten J, De Hullu JA: New FIGO staging system of vulvar cancer indeed provides a better reflection of prognosis. Gynecol Oncol 2010, 119:520-525.

43. Woelber L, Eulenburg C, Choschzick M, Kruell A, Petersen C, Gieseking F, Jaenicke F, Mahner S: Prognostic role of lymph node metastases in vulvar cancer and implications for adjuvant treatment. Int J Gynecol Cancer 2012, 22:503-508.

44. Woelber L, Mahner S, Voelker K, Eulenburg CZ, Gieseking F, Choschzick M, Jaenicke F, Schwarz J: Clinicopathological prognostic factors and patterns of recurrence in vulvar cancer. Anticancer Res 2009, 29:545-552.

45. Fox SB, Leek RD, Weekes MP, Whitehouse RM, Gatter KC, Harris AL: Quantitation and prognostic value of breast cancer angiogenesis: comparison of microvessel density, Chalkley count, and computer image analysis. J Pathol 1995, 177:275-283.

46. Birner P, Schindl M, Obermair A, Plank C, Breitenecker G, Oberhuber G: Overexpression of hypoxia-inducible factor 1alpha is a marker for an unfavorable prognosis in early-stage invasive cervical cancer. Cancer Res 2000, 60:4693-4696.

47. Shibata-Kobayashi S, Yamashita H, Okuma K, Shiraishi K, Igaki H, Ohtomo K, Nakagawa K: Correlation among 16 biological factors [p53, p21(waf1), MIB-1 (Ki-67), p16(INK4A), cyclin D1, E-cadherin, Bcl-2, TNF-alpha, NF-kappaB, TGF-beta, MMP-7, COX-2, EGFR, HER2/neu, ER, and HIF-1alpha] and clinical outcomes following curative chemoradiation therapy in 10 patients with esophageal squamous cell carcinoma. Oncol Lett 2013, 5:903-910.

48. Keith B, Johnson RS, Simon MC: HIF1alpha and HIF2alpha: sibling rivalry in hypoxic tumour growth and progression. Nat Rev Cancer 2012, 12:9-22.

49. Guo K, Searfoss G, Krolikowski D, Pagnoni M, Franks C, Clark K, Yu KT, Jaye $M$, Ivashchenko $Y$ : Hypoxia induces the expression of the pro-apoptotic gene BNIP3. Cell Death Differ 2001, 8:367-376.

50. Sowter HM, Ratcliffe PJ, Watson P, Greenberg AH, Harris AL: HIF-1-dependent regulation of hypoxic induction of the cell death factors BNIP3 and NIX in human tumors. Cancer Res 2001, 61:6669-6673.

51. Lichtenberger BM, Tan PK, Niederleithner H, Ferrara N, Petzelbauer P, Sibilia M: Autocrine VEGF signaling synergizes with EGFR in tumor cells to promote epithelial cancer development. Cell 2010, 140:268-279.

52. Cao Y, Ei G, Wang E, Pal K, Dutta SK, Bar-Sagi D, Mukhopadhyay D: VEGF exerts an angiogenesis-independent function in cancer cells to promote their malignant progression. Cancer Res 2012, 72:3912-3918.

53. Yoshiji H, Harris SR, Thorgeirsson UP: Vascular endothelial growth factor is essential for initial but not continued in vivo growth of human breast carcinoma cells. Cancer Res 1997, 57:3924-3928. 
54. Cao Y, Li CY, Moeller BJ, Yu D, Zhao Y, Dreher MR, Shan S, Dewhirst MW: Observation of incipient tumor angiogenesis that is independent of hypoxia and hypoxia inducible factor-1 activation. Cancer Res 2005, 65:5498-5505.

55. Mighell AJ, Hume WJ, Robinson PA: An overview of the complexities and subtleties of immunohistochemistry. Oral Dis 1998, 4:217-223.

56. Skaland I, Nordhus M, Gudlaugsson E, Klos J, Kjellevold KH, Janssen EA, Baak JP: Evaluation of 5 different labeled polymer immunohistochemical detection systems. Appl Immunohistochem Mol Morphol 2010, 18:90-96.

57. Warren MV, Chan WY, Ridley JM: Analysis of protein biomarkers in human clinical tumor samples: critical aspects to success from tissue acquisition to analysis. Biomark Med 2011, 5:227-248.

doi:10.1186/1471-2407-13-506

Cite this article as: Dhakal et al:: Primary Tumor Vascularity, HIF-1a and VEGF expression in vulvar squamous cell carcinomas: their relationships with clinicopathological characteristics and prognostic impact. BMC Cancer 2013 13:506.

\section{Submit your next manuscript to BioMed Central and take full advantage of:}

- Convenient online submission

- Thorough peer review

- No space constraints or color figure charges

- Immediate publication on acceptance

- Inclusion in PubMed, CAS, Scopus and Google Scholar

- Research which is freely available for redistribution 